\title{
BMJ Open Could COVID-19 pandemic be stopped with joint efforts of travel restrictions and public health countermeasures? A modelling study
}

\author{
Lingcai Kong, ${ }^{1}$ Yi Hu, ${ }^{2}$ Qiang Wang (D , ${ }^{3}$ Xinda Chen, ${ }^{1}$ Tong Yao, ${ }^{1}$ Yu Wang, ${ }^{4}$ \\ Hui Jin (D) , ${ }^{3}$ Lijun Fan, ${ }^{3}$ Wei Du (iD ${ }^{3}$
}

To cite: Kong L, Hu Y, Wang Q, et al. Could COVID-19 pandemic be stopped with joint efforts of travel restrictions and public health countermeasures? A modelling study. BMJ Open 2021;11:e046157. doi:10.1136/ bmjopen-2020-046157

- Prepublication history and additional supplemental material for this paper are available online. To view these files, please visit the journal online (http://dx.doi.org/10.1136/ bmjopen-2020-046157).

LK and YH contributed equally.

Received 24 October 2020 Revised 19 January 2021 Accepted 15 April 2021

\section{Check for updates}

(c) Author(s) (or their employer(s)) 2021. Re-use permitted under CC BY-NC. No commercial re-use. See rights and permissions. Published by BMJ.

${ }^{1}$ Department of Mathematics and Physics, North China Electric Power University, Baoding, China

${ }^{2}$ Department of Epidemiology and Biostatistics, Fudan University, Shanghai, China ${ }^{3}$ Key Laboratory of Environmental Medicine Engineering, School of Public Health, Southeast University, Nanjing, China

${ }^{4}$ Department of Global Health, Peking University, Beijing, China

Correspondence to

ProfWei Du; duwei@seu.edu.cn

\section{ABSTRACT}

Objective We aim to explore and compare the effect of global travel restrictions and public health countermeasures in response to COVID-19 outbreak. Design A data-driven spatio-temporal modelling to simulate the spread of COVID-19 worldwide for 150 days since 1 January 2020 under different scenarios.

Setting Worldwide.

Interventions Travel restrictions and public health countermeasures.

Main outcome The cumulative number of COVID-19 cases.

Results The cumulative number of COVID-19 cases could reach more than 420 million around the world without any countermeasures taken. Under timely and intensive global interventions, $99.97 \%$ of infections could be avoided comparing with non-interventions. The scenario of carrying out domestic travel restriction and public health countermeasures in China only could contribute to a significant decrease of the cumulative number of infected cases worldwide. Without global travel restriction in the study setting, $98.62 \%$ of COVID-19 cases could be avoided by public health countermeasures in China only compared with non-interventions at all.

Conclusions Public health countermeasures were generally more effective than travel restrictions in many countries, suggesting multinational collaborations in the public health communities in response to this novel global health challenge.

\section{INTRODUCTION}

Novel infectious diseases appear to be emerging faster now than ever before, possibly driven by the systematic manipulation of nature by humans, not only through a variety of factors, including population growth, cross-species interactions, climate change and international travel and trade, yet also through weakening of natural barriers to disease emergence and persistence. Globally, as at 18 October 2020, a total of 39442 444 people have been confirmed COVID-19 cases, including 1039406 deaths, reported by the WHO. ${ }^{1}$ WHO declared COVID-19 a
Strengths and limitations of this study

- Under timely and intensive global interventions in the study setting, $99.97 \%$ of infections could be avoided comparing with non-interventions.

- The scenario of carrying out domestic travel restriction and public health countermeasures in China only could contribute to a significant decrease of the cumulative number of infected cases worldwide.

- Public health countermeasures were generally more effective than travel restrictions in many countries, suggesting multinational collaborations in the public health communities in response to this novel global health challenge.

- The analysis was limited to the study time. Our hypothetical scenarios were based on counterfactual and backtrack the results to compare with the current situations.

Public Health Emergency of International Concern on 30 January $2020^{2}$ and then a pandemic on 9 March and called on Member States to respond to the COVID-19 pandemic by implementing nationwide COVID-19 countermeasure strategies.

In the absence of effective drugs and vaccines, non-pharmaceutical interventions were effective in controlling the SARS-CoV-2 transmission in different populations. ${ }^{34} \mathrm{~A}$ series of social distancing countermeasures including school closures and restriction on mass gathering were implemented to minimise risk of spread between humans. Travel restrictions were enforced by several countries to uphold border security and shut down the transmission passage from any imported infected cases. The decline of COVID-19 cases in China showed the effectiveness of nonpharmaceutical public health interventions, with their implementation exceptionally stringent as compared with most other countries. ${ }^{5}$ However, over the past 8 months, the 
number of cases reported has increased rapidly without showing signs of decay around the world. Selection and implementation of intervention strategies appeared to be different across countries and regions in their responses to the early sign of disease spread, which could explain in part the current COVID-19 pandemic.

In February and March, WHO did not recommend imposing travel or trade restrictions on countries experiencing COVID-19 outbreaks. ${ }^{6}$ The International Health Regulations (2005) formulated the global joint response to the disease in order to avoid unnecessary international traffic and trade restrictions. ${ }^{7}$ WHO commented that travel and trade restrictions would cause more harm than good. ${ }^{8}$ More than 130 countries have implemented different forms of travel restrictions, including suspensions of flights, halting visa-on-arrival programmes, discouraging travel to and from high-risk areas and closing borders for foreigners. ${ }^{9}$ Recently, a few reports explored the effectiveness of travel restrictions on COVID-19 in different countries. ${ }^{1011}$ To some extent, travel restrictions avoided the importation of infected cases by breaking the chains of transmission between different locations; however, the containment effect on COVID-19 pandemic was unknown. Nonetheless, an Australian study showed the travel restrictions to and from China were somewhat effective on containing the COVID-19 spread. ${ }^{12}$

The purpose of this study was to compare the current situations with our assumed scenarios under different intervention strategies to explore the effectiveness of different interventions in containing the COVID-19 transmission. Findings may support local decision makers to select intervention strategies particularly in relation to travel restrictions to prevent, contain and manage COVID-19 spread in the nearer future.

\section{METHODS}

\section{Data sources}

Size of population by country were obtained from Worldometer. ${ }^{13}$ Air flights data were obtained from the OpenFlights databases, ${ }^{14}$ which contains information of 7698 airports and 67663 domestic and international routes and other related data. International routes were aggregated to the country level. Although number of travellers would most accurately reflect the population mobility, this exact information was not available; hence, we used the aircraft seating capacity as the best available proxy measure for analysis relating to number of travellers.

Information on travel restrictions against China was obtained from the National Immigration Administration (https://www.nia.gov.cn/) and complemented with information from the council on foreign relations (https:// www. thinkglobalhealth.org/article/travel-restrictionschina-due-covid-19). Other travel restriction information was obtained from the International Air Transport Association (IATA) updated on 1 April 2020 (www.iatatravelcentre.com/international-travel-document-news).

\section{Epidemic simulation model}

We employed the SimInf $\mathrm{R}$ package to implement the COVID-19 spatio-temporal modelling. ${ }^{15} 16$ The model comprised multiple nodes and each node, representing one country, contained the susceptible (S), exposed (E), infected (I) and removed (R) compartments. Transitions between these compartments were modelled as a continuous-time discrete state Markov chain. Individuals' movements across different countries, which were estimated by the aircraft seating capacity as the proxy for number of travellers, were processed with scheduled events, causing the change of the population in each country. We only considered the movement of individuals in one country to a destination country, irrespective of the birth or death. The scheduled movements were carried on when the simulation in continuous time reaches the predefined time. The individuals were randomly sampled from the compartments affected by the event. At time $t$, there were $a_{i j, t}$ susceptible individuals moved from node $i$ to $j$, while $a_{j i, t}$ susceptible individuals moved from $j$ to $i$. The number of exposed, infected and removed individuals travelled from country $i$ to $j$ were noted by $b_{i j, t} c_{i, j}$ and $d_{i j, t}$, respectively. Transitions between compartments in one country and the movements between different countries were illustrated by figure 1 . The number of individuals' movements across countries were estimated to represent different scenarios. We implemented a classic SEIR transmission model to simulate the spread of COVID-19. For simplicity, we presented the deterministic version of the transmission model in each country, described by the following set of differential equations:

$$
\begin{gathered}
\frac{\mathrm{d} S}{\mathrm{~d} t}=-\frac{\beta S I}{N} \\
\frac{\mathrm{d} E}{\mathrm{~d} t}=\frac{\beta S I}{N}-\sigma E \\
\frac{\mathrm{d} I}{\mathrm{~d} t}=\sigma E-\gamma I \\
\frac{\mathrm{d} R}{\mathrm{~d} t}=\gamma I
\end{gathered}
$$

where $1 / \sigma$ is the latent period with value of 6.4 days, and $1 / \gamma$ is the recovery period with value of days. ${ }^{17} 18$ In our model, we set the reproductive number, $R_{0}=2.35$, corresponding to the effective contact rate $\beta=0 \cdot 8103 .{ }^{18}$

We assumed 10 initial infectious cases of COVID-19 identified from Wuhan City of China. The number of susceptible individuals were set to the size of population in each country, while the number of exposed and recovered were all set to zero. We ran the models for 150 days and used the cumulative number of infections to investigate the influence of travel restrictions and public health countermeasures including social distancing, isolation of cases, quarantine of close contacts, etc, during the global spread of COVID-19. The first day of the simulation was set on 1 January 2020.

\section{Modelling scenarios}

Seven scenarios were modelled to simulate the spread of COVID-19 around the world (table 1). The baseline scenario for comparison was set assuming neither travel restrictions nor public health countermeasures. 


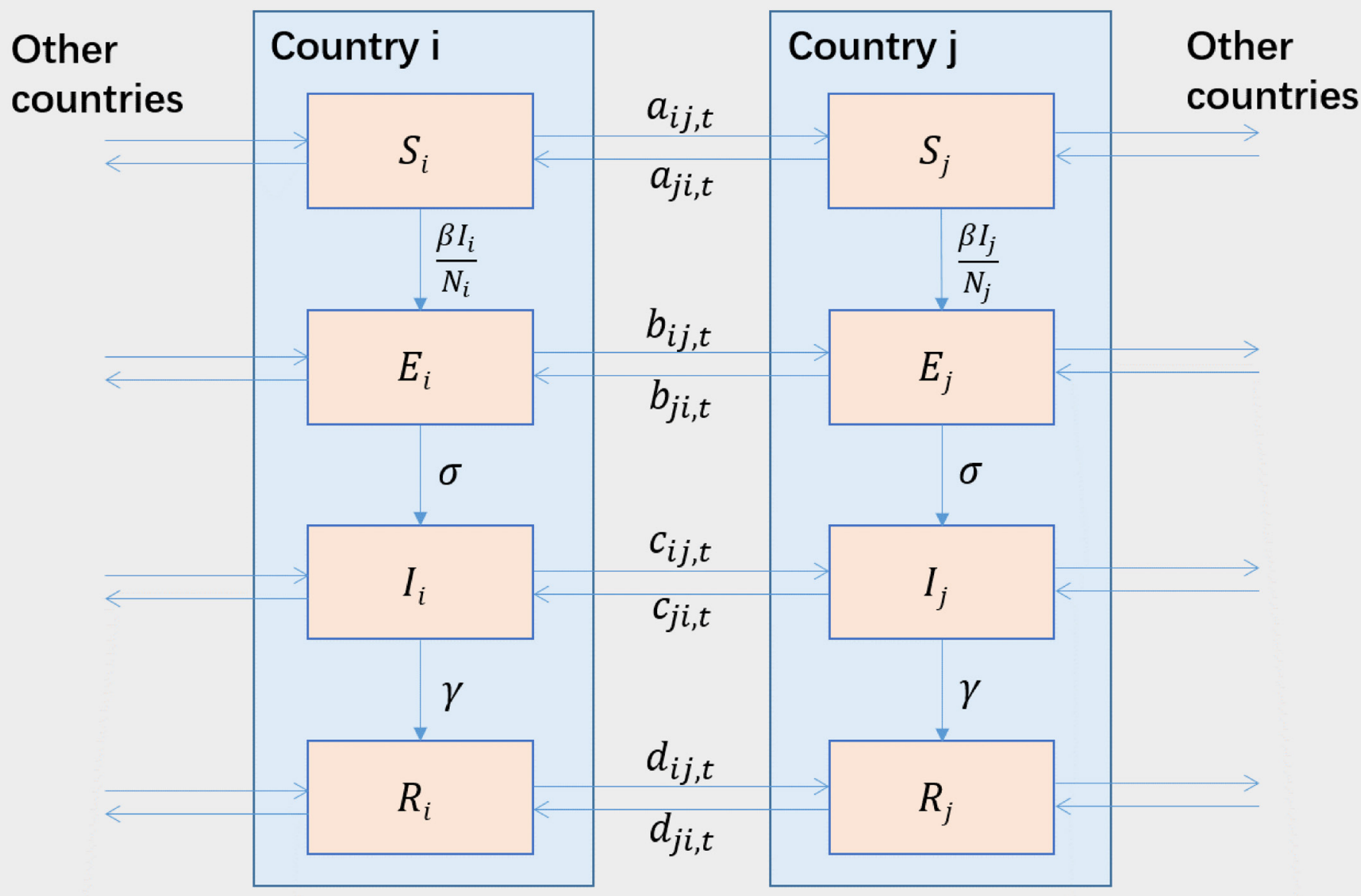

Figure 1 The flow chart of transitions between compartments and movements between countries.

Additional six scenarios were then modelled assuming different combination of travel restrictions and public health countermeasures.

We separated global travel restrictions into three situations, that is, none, travel restrictions against China or multinational travel restrictions. After WHO declared COVID-19 a Public Health Emergency of International Concern, many countries imposed travel restrictions against China, most of which were effective on 1 February, 2020. Since March 2020, COVID-19 has spread around almost everywhere in the world. Responsive to this pandemic, country-wide travel bans were implemented strictly worldwide. We collected the information on multinational travel bans from IATA $^{19}$ (updated on 1 April 2020), from which we assumed global travel restrictions were carried out on 20 March 2020.

We separated the public health countermeasures into three situations, that is, none, public health countermeasures implemented in China, or global public health countermeasures implemented worldwide. In the study, public health countermeasures represented a series of activities reducing effective contact rate between humans.

Table 1 Assumed scenarios to simulate the spread of COVID-19

\begin{tabular}{lllll}
\hline Scenarios & $\begin{array}{l}\text { Travel restrictions } \\
\text { against China (from } \\
\text { 1 February) }\end{array}$ & $\begin{array}{l}\text { Global travel } \\
\text { restrictions (from } \\
\text { 20 March) }\end{array}$ & $\begin{array}{l}\text { Public health } \\
\text { countermeasures in } \\
\text { China (from 25 January) }\end{array}$ & $\begin{array}{l}\text { Global public health } \\
\text { countermeasures (from } \\
\text { 25 January) }\end{array}$ \\
\hline 1 (baseline) & No & No & No & No \\
2 & Yes & No & No & No \\
3 & No & No & Yes & No \\
4 & Yes & No & Yes & No \\
5 & Yes & Yes & No & No \\
6 & Yes & Yes & Yes & Yes \\
\hline 7 & Yes & Yes & Yes & \\
\hline
\end{tabular}


Table 2 Results for the run with median of the total cumulative number of infections

\begin{tabular}{llll}
\hline Scenarios & $\begin{array}{l}\text { Median of cumulative } \\
\text { infections at } \mathbf{1 5 0} \text { days }\end{array}$ & $\begin{array}{l}\text { Avoided median } \\
\text { number of cases }\end{array}$ & $\begin{array}{l}\text { Reducing the estimated median number of } \\
\text { infections (\%) }\end{array}$ \\
\hline 1 (baseline) & 420520763 & - & - \\
\hline 2 & 385399261 & 35121502 & 8.35 \\
3 & 5809925 & 414710838 & 98.62 \\
\hline 4 & 4832306 & 415688457 & 98.85 \\
\hline 6 & 417781694 & 2739069 & 0.65 \\
\hline 7 & 5270174 & 415250589 & 98.75 \\
\hline Actual reportingt & 5708365 & 420387188 & 99.97 \\
\hline
\end{tabular}

${ }^{*}$ Compared with infections in baseline 1 .

†Number of confirmed cases were derived from WHO data reported on 29 May 2020 (150th day since 1 January 2020).

These activities included isolating confirmed cases, quarantining close contacts, suspending public transports, closing schools and entertainment venues and banning public gatherings. ${ }^{20}$ These public health countermeasures have been put in place to stop transmission of COVID-19 since late January 2020, which demonstrated a reduced daily contact by most, during the COVID-19 social distancing period, with most human interactions restricted to be held within each household. ${ }^{21}$ We assumed the global public health countermeasures were implemented in a less strict way than those in China. Therefore, for public health countermeasures implemented in China, we set the effective contact rate in China reducing $85 \%$ after 24 January 2020, whereas for global public health countermeasures, we set the effective contact rate among other countries reducing $50 \%$ from 25 January 2020.

\section{Patient and public involvement statement}

Patients and the public were not involved in this study.

\section{RESULTS}

Table 2 presented the median estimates of the total cumulative number of infections worldwide for each scenario. The cumulative cases would have reached more than 420 million if no countermeasures had been taken. On 29 May, there were 5708365 cases reported by WHO. The numbers of cases under scenarios 2 and 5 were far more than the actual reporting data, respectively, whereas that under scenario 3 were similar to the actual reporting data. The absolute number of cases in scenario 7 were far lower than the actual reporting data.

Interventions implemented in China contributed to the significant decline in the cumulative number of infections worldwide according to the scenarios 3, 4 and 6 in comparison with no action taken at all. In scenario 3, 98.62\% of COVID-19 cases could have been avoided compared with the no-action baseline scenario. Implementing travel restrictions against China alone (scenario 2) had little effect on the controlling of global spread of COVID-19, as no substantial reduction in cases was observed. In scenario 5, implementing international travel restrictions could have only avoided $0.65 \%$ of number of infected cases in comparison with the no-action baseline scenario. Figures 2-3 and online supplemental figures 1-5 showed the spatial distribution of the cumulative number of infected cases over 150 days in each scenario.

\section{DISCUSSION}

Our modelling results showed that COVID-19 transmission could be contained by timely and intensive travel restrictions and public health countermeasures with multinational joint efforts at the early stage of spread, and consequently the risk of becoming pandemic could perhaps be mitigated. Haug et $a l^{22}$ quantified the change of Rt (ie, the effective reproduction number of COVID-19, an indicator to measure the transmission of SARS-CoV-2, defined as the mean number of secondary cases generated by a primary case at time $t$ in a population) in relation to different adoption time of non-pharmaceutical interventions and reported that the earlier adoptions were associated with more benefits. China's rapid responses to the COVID-19 spread also demonstrated a successful case in the real world. ${ }^{5}$ While the spread of the pandemic follows an exponential pattern during the initial growth phase, it is particularly important to uptake the effective intervention strategies as early as possible, especially when facing the COVID-19 resurgence spread.

Reduction in cumulative infections and local transmissions of COVID-19 was somewhat attributed towards the aggregated public health countermeasures, and to a much lesser extent, international travel restrictions, which was consistent with previous studies using a similar analytic approach. Chinazzi et $a l^{23}$ reported impose travel restrictions on mainland China had a modest effect on the epidemic trajectory. Wells et $a l^{10}$ showed that the travel restrictions as well as airport screening enforced in China and other countries were insufficient to contain the COVID-19 spread around the world. ${ }^{10}$ Russell et $a l^{24}$ 


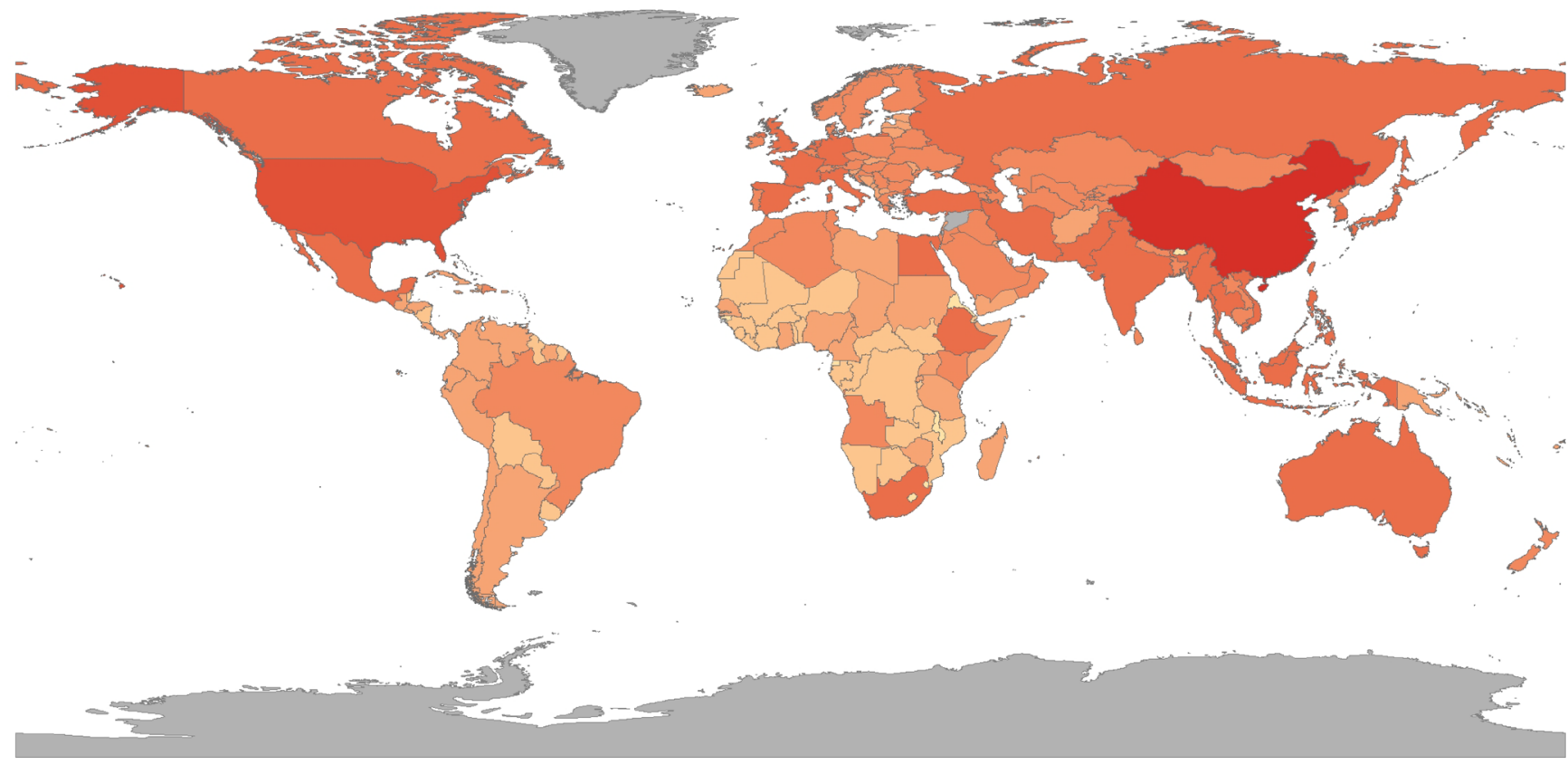

\section{Legend}

\section{Confirmed cases in Scenatio1}
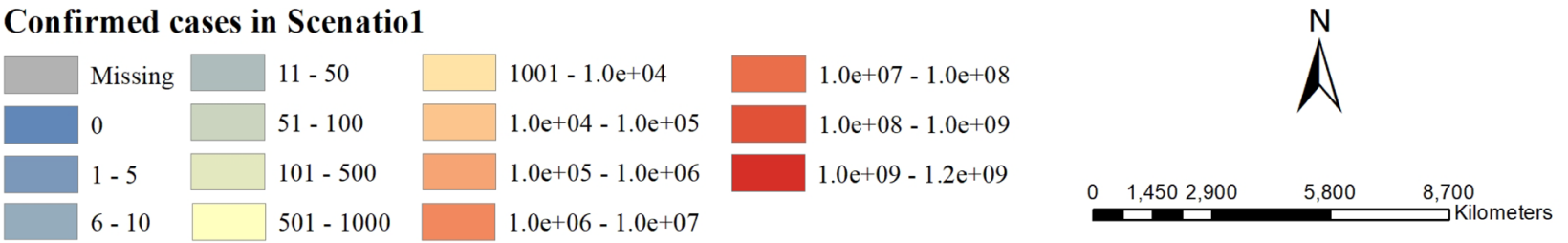

Figure 2 Cumulative cases at days 150 in scenario 1.

found that in general stringent travel restrictions might have little impact on the epidemic dynamics. Given several factors including complex human behaviours that could determine the spread of the current pandemic, lessons learnt from China's experience could be informative to initiate multiple public heath countermeasures such as the grid-network of community-based health checkpoints, ${ }^{5}$ when facing a COVID-19 resurgence spread at present. Our study findings emphasised again the importance of carrying out collaborative public health countermeasures rather than simply placing travel restrictions.

Compared with previously reported number of COVID-19 cases, ${ }^{1}$ those predicted under scenarios of either imposing travel restrictions against China or implementing global travel restrictions were greater than the real-world observations. That is, these strategies appeared to be ineffective or somewhat exaggerated. This finding indicated the intervention strategies implemented in China have played an important role on the control of COVID-19 spread in communities. On 23 January, authorities in Wuhan have taken a series of unprecedented COVID-19 countermeasures with millions of local residents strictly upholding these policies, including city lockdown, traffic suspension and quarantine. ${ }^{25}$ Recent epidemiological studies have demonstrated that these interventions have contributed to the interruption of the spread of SARS-CoV-2 transmission, ${ }^{25}{ }^{26}$ which was consistent with our modelling analysis. The decrease of daily COVID-19 infections in China has provided another set of evidence of the field effectiveness of these public health countermeasures. ${ }^{5}$

Ideally, should most of the countries around the world have taken public health countermeasures including stockpiling medical resources, initiating emergency response procedures, screening high-risk population and promoting social distancing at the beginning of the epidemic outbreak, the global spread of COVID-19 could have been restricted to a much lesser extent around the world (scenario 7). However, as of 29 May, there were 5708365 cases reported by WHO, greater than the simulated finding under scenario of every member state taking precautionary countermeasures as early as January when city quarantine in China has been initiated. Compared with what we assumed that the public health countermeasures should have been carried out around the world from January 25, there was a 2-month window period during which the global health communities did not effectively responded. European countries began to implement a series of intervention strategies since midMarch $2020 .^{3}$ The stay-at-home order has been issued in 


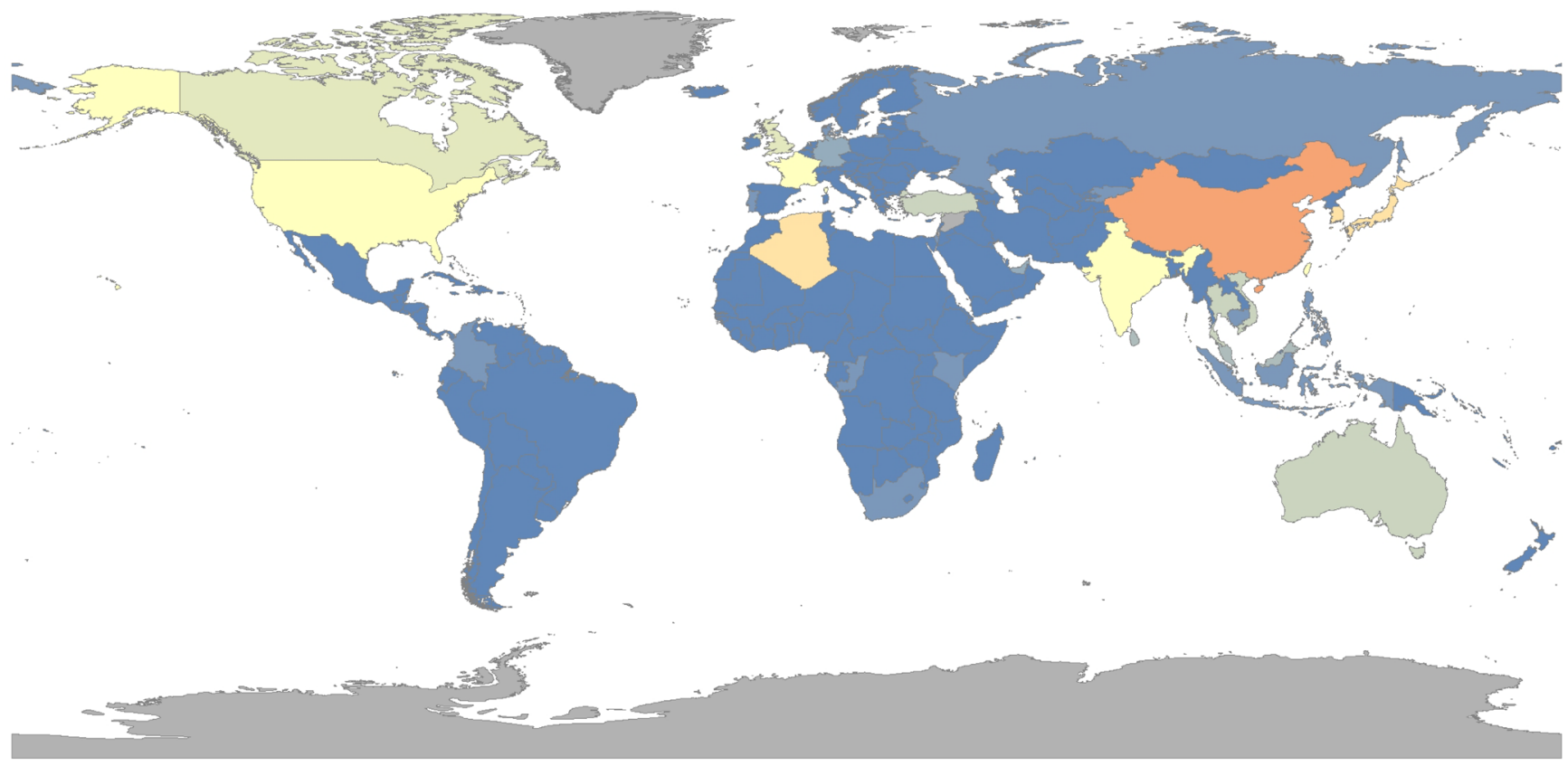

\section{Legend}

Confirmed cases in Scenatio6

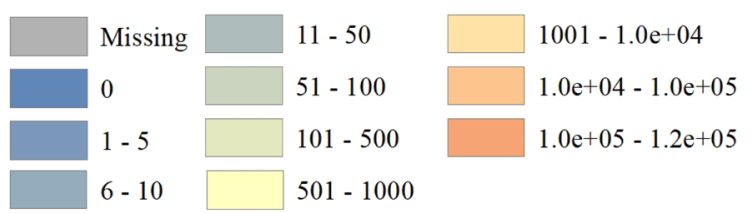

Figure 3 Cumulative cases at days 150 in scenario 7.

the 42 states of USA in late March and early April. ${ }^{27}$ Facing a possible reemergence of COVID-19 later this year, any countermeasures that have been proved effective in the field should have been implemented timely and strictly around the world.

The global travel restriction played a relatively modest preventive role on controlling the SARS-CoV-2 transmission in our analysis, which was consistent with previous studies. ${ }^{102}$ While any global travel bans could slow the rate of importing cases, but they cannot stop the spread of COVID-19 around the world. ${ }^{10} \mathrm{~A}$ systematic review of 23 studies has showed the travel restrictions were effective in delaying the epidemic trajectory but ineffective in stopping it. ${ }^{29}$ Other concerns about the global travel restriction strategy include its consequences of global economic issues as well as social dissatisfaction in relation to human rights and discrimination. ${ }^{30}$ Furthermore, one trade-off of the global travel restrictions would be related to a possible delay of appropriate responses in low-income countries because a large amount of medical resources via air transportation from developed countries could have been blocked down. ${ }^{9}$ While the variation in effectiveness of partial or entire travel ban was under investigation, ${ }^{12} 28$ our findings suggest travel restriction a somewhat robust strategy during the outbreak. Additional efforts may invest on screening and quarantining travellers from high-risk regions at the transportation interchange and remain social distancing strategies in the communities.

Our study has some limitations. First, our analysis was limited to the study time at the early stage of COVID-19 spread. Our hypothetical scenarios were based on counterfactual and backtrack the results to compare with the current situations. Second, the finding of substantial variation in the geographic spread across countries reflected heterogenetic contact rates in different countries. Although the summary statistics around the world demonstrated a global benefit by means of public health interventions, each member state is encouraged to select appropriate countermeasures in its own setting to minimise the risk of COVID-19 resurgence spread becoming endemic. Third, we assumed aggregated strategies that could vary across different settings, and therefore, result should be interpreted with caution. Nonetheless, the rapid spread of this novel infectious diseases demonstrated adverse impact on the entire world with harms to the global health, economy and social governance. The COVID-19 pandemic has posed a major threat to our society, and no country could be immune to such complex issues and stay out of the multinational collaborations. In the face of this global challenge, the principle 
of one health and one world should be encouraged by all nations to achieve global governance in public health.

\section{CONCLUSION}

Number of COVID-19 infected cases around the world could have been largely prevented by public health countermeasures in each country and, to a lesser extent, by the global travel restriction. Rapid response to this novel public health challenge requires multinational collaborations to carry out timely and intensive intervention strategies.

Acknowledgements We would like to thank Professor Yilan Liao for her advice and critical comments.

Contributors Conception and design of the work: WD, LK and YH; acquisition of data: LK and YH; statistical analysis: LK and YH; interpretation of data: WD, LK and $\mathrm{YH}$; drafted the manuscript and revised: all authors. All authors revised the manuscript and read and approved the final version.

Funding This study was supported by the Department of Education (No. 1125000172), National Science and Technology Major Project of China (No. 2018ZX10713001), Jiangsu Provincial Major Science \& Technology Demonstration Project (No. BE2017749), National Natural Science Foundation of China (Grant Number: 41101431, 41531179, 41421001, 41471377, 71704192) and Fundamental Research Funds for the Central Universities (No. 2017BD0094/3225002002A1)

Competing interests None declared.

Patient consent for publication Not required.

Ethics approval Provincial Health Commissions in mainland of China have reported municipal-level incident numbers of COVID-19 suspected, confirmedly infected, recovered and deceased individuals, respectively on a daily basis since January 2020. These data were publically available, and therefore, this study was exempted for ethics approval by institutional review boards with respect to data collection, analysis and reporting.

Provenance and peer review Not commissioned; externally peer reviewed.

Data availability statement Data are available on reasonable request. Requests for data access should be directed to the corresponding author.

Supplemental material This content has been supplied by the author(s). It has not been vetted by BMJ Publishing Group Limited (BMJ) and may not have been peer-reviewed. Any opinions or recommendations discussed are solely those of the author(s) and are not endorsed by BMJ. BMJ disclaims all liability and responsibility arising from any reliance placed on the content. Where the content includes any translated material, BMJ does not warrant the accuracy and reliability of the translations (including but not limited to local regulations, clinical guidelines, terminology, drug names and drug dosages), and is not responsible for any error and/or omissions arising from translation and adaptation or otherwise.

Open access This is an open access article distributed in accordance with the Creative Commons Attribution Non Commercial (CC BY-NC 4.0) license, which permits others to distribute, remix, adapt, build upon this work non-commercially, and license their derivative works on different terms, provided the original work is properly cited, appropriate credit is given, any changes made indicated, and the use is non-commercial. See: http://creativecommons.org/licenses/by-nc/4.0/.

\section{ORCID iDs}

Qiang Wang http://orcid.org/0000-0002-1393-2443

Hui Jin http://orcid.org/0000-0001-8790-2434

Wei Du http://orcid.org/0000-0003-3622-2265

\section{REFERENCES}

1 World Health Organization. Coronavirus disease 2019 (COVID-19) Dashboard, 2020. Available: https://covid19.who.int/

2 World Health Organization. Statement on the second meeting of the International health regulations (2005) emergency Committee regarding the outbreak of novel coronavirus (2019nCoV), 2020.
Available: https://www.who.int/news/item/30-01-2020-statementon-the-second-meeting-of-the-international-health-regulations-( 2005)-emergency-committee-regarding-the-outbreak-of-novelcoronavirus-(2019-ncov)

3 Flaxman S, Mishra S, Gandy A, et al. Estimating the effects of non-pharmaceutical interventions on COVID-19 in Europe. Nature 2020;584:257-61.

4 Lai S, Ruktanonchai NW, Zhou L, et al. Effect of non-pharmaceutical interventions to contain COVID-19 in China. Nature 2020:585:410-3.

5 Burki T. China's successful control of COVID-19. Lancet Infect Dis 2020;20:1240-1.

6 World Health Organization. Updated WHO recommendations for international traffic in relation to COVID-19 outbreak, 2020. Available: https://www.who.int/news-room/articles-detail/updated-whorecommendations-for-international-traffic-in-relation-to-covid-19outbreak

7 World Health Organization. International health regulations, WHA 58.3. 2nd edn. Geneva: World Health Organization, 2005.

8 WHO. World Health Organization Director-General's statement on IHR Emergency Committee on Novel Coronavirus (2019-nCoV)., 2020. Available: https://www.who.int/dg/speeches/detail/whodirector-general-s-statement-on-ihr-emergency-committee-on-novelcoronavirus-(2019-nCoV)

9 Devi S. Travel restrictions hampering COVID-19 response. Lancet 2020;395:1331-2.

10 Wells CR, Sah P, Moghadas SM, et al. Impact of international travel and border control measures on the global spread of the novel 2019 coronavirus outbreak. Proc Natl Acad Sci U S A 2020;117:7504-9.

11 Anzai A, Kobayashi T, Linton NM, et al. Assessing the impact of reduced travel on exportation dynamics of novel coronavirus infection (COVID-19). J Clin Med 2020;9:601.

12 Costantino V, Heslop DJ, Maclntyre CR. The effectiveness of full and partial travel bans against COVID-19 spread in Australia for travellers from China during and after the epidemic peak in China. $J$ Travel Med 2020;27:taaa081.

13 Worldometer. Countries in the world by population, 2020. Available: https://www.worldometers.info/world-population/population-bycountry/

14 Openflights. Airport, airline and route data, 2020. Available: https:// openflights.org/data.html

15 et alWidgren S, Eriksson R, Engblom S. Simlnf: a framework for data-driven stochastic disease spread simulations, 2020. Available: https://CRAN.R-project.org/package =Simlnf

16 Widgren S, Bauer P, Eriksson R, et al. Simlnf : An R Package for Data-Driven Stochastic Disease Spread Simulations. J Stat Softw 2019;91:42.

17 Backer JA, Klinkenberg D, Wallinga J. Incubation period of 2019 novel coronavirus (2019-nCoV) infections among travellers from Wuhan, China, 20-28 January 2020. Euro Surveill 2020;25.

18 Kucharski AJ, Russell TW, Diamond C, et al. Early dynamics of transmission and control of COVID-19: a mathematical modelling study. Lancet Infect Dis 2020;20:553-8.

19 International Air Transport Association (IATA). Travel news powered by IATA Timatic, 2020. Available: https://www.iatatravelcentre.com/ international-travel-document-news/1580226297.htm

20 Tian $\mathrm{H}$, Liu Y, Li Y, et al. An investigation of transmission control measures during the first 50 days of the COVID-19 epidemic in China. Science 2020;368:638-42.

21 Zhang J, Litvinova M, Liang Y, et al. Changes in contact patterns shape the dynamics of the COVID-19 outbreak in China. Science 2020;368:1481-6.

22 Haug N, Geyrhofer L, Londei A, et al. Ranking the effectiveness of worldwide COVID-19 government interventions. Nat Hum Behav 2020;4:1303-12.

23 Chinazzi M, Davis JT, Ajelli M, et al. The effect of travel restrictions on the spread of the 2019 novel coronavirus (COVID-19) outbreak. Science 2020;368:395-400.

24 Russell TW, Wu JT, Clifford S, et al. Effect of internationally imported cases on internal spread of COVID-19: a mathematical modelling study. Lancet Public Health 2021;6:e12-20.

25 Pan A, Liu L, Wang C, et al. Association of public health interventions with the epidemiology of the COVID-19 outbreak in Wuhan, China. JAMA 2020;323:1915-9.

26 Zhang J, Litvinova M, Wang W, et al. Evolving epidemiology and transmission dynamics of coronavirus disease 2019 outside Hubei Province, China: a descriptive and modelling study. Lancet Infect Dis 2020;20:793-802.

27 Johns Hopkins University. COVID-19 dashboard, 2020. Available: https://coronavirus.jhu.edu/map.html 
28 Castillo RC, Staguhn ED, Weston-Farber E. The effect of statelevel stay-at-home orders on COVID-19 infection rates. Am J Infect Control 2020;48:958-60.

29 Mateus ALP, Otete HE, Beck CR, et al. Effectiveness of travel restrictions in the rapid containment of human influenza: a systematic review. Bull World Health Organ 2014;92:868-80.
30 von Tigerstrom B, Wilson K. COVID-19 travel restrictions and the International Health Regulations (2005). BMJ Glob Health 2020;5:e002629. 